\title{
THE DEPTH OF SEISMIC FAULTING AND THE UPPER TRANSITION FROM STABLE TO UNSTABLE SLIP REGIMES
}

\author{
Chris Marone and C. H. Scholz
}

\author{
Lamont-Doherty Geological Observatory and Department of Geological Sciences, Columbia University
}

\begin{abstract}
A number of observations indicate that an upper stability transition occurs along well-developed faults, such as the San Andreas, as a result of unconsolidated gouge within shallow regions of these faults. These observations include the depth distribution of seismicity along faults with and without well-developed gouge zones, correlations between seismicity and shallow crustal structure, and modeling of coseismic and post-seismic slip. In addition, recent experimental friction studies indicate that thick layers of simulated gouge exhibit a positive slip-rate dependence of frictional resistance (velocity strengthening) and thus inherently stable slip, whereas bare rock surfaces and thin gouge layers exhibit potentially unstable velocity weakening behavior. Subduction zones with large accretionary wedges also exhibit an upper stability transition in that slip is aseismic within the accretionary wedge. A stability transition due to the presence of unconsolidated material can also be invoked in this case.
\end{abstract}

\section{Introduction}

Detailed microearthquake studies along the San Andreas and other well-developed faults commonly show a confinement of hypocenters to between ca. 3 and $14 \mathrm{~km}$ depth [Eaton et al. 1970; Reasenberg and Ellsworth, 1982]. The lower boundary of this seismogenic zone has been attributed to a transition from brittle to ductile deformation [e.g., Sibson, 1977]. Recently, this explanation has been refined by Tse and Rice [1986] who show that the base of the seismogenic zone can be understood solely as a transition from unstable to stable frictional slip due to increasing temperature. In contrast, the upper cutoff in seismicity, between $3-5 \mathrm{~km}$ along well-developed faults, has received little attention.

In this paper we examine the transition in frictional stability indicated by the upper cutoff in seismicity along welldeveloped faults. We consider faults well-developed if they have undergone significant net displacement, and as a result, contain thick zones of wear material (gouge) [Robertson, 1983; Scholz, 1987]. The upper cutoff in seismicity has generally been attributed to the stabilizing effect of low normal stress or the effects of pore fluids and dilatancy hardening. In the case of low normal stress, shallow seismicity should either be absent along all faults or its absence should correlate with the mode of faulting (i.e., normal vs. thrust). However, as we show here, seismic data indicate that only welldeveloped faults exhibit an upper cutoff in seismicity; poorly-

Copyright 1988 by the American Geophysical Union.

Paper number $8 \mathrm{~L} 7312$.

0094-8276/88/008L-7312\$03.00 developed faults, those which have little to no net slip and thus do not have appreciable gouge zones, undergo seismic failure throughout their upper regions. Also, the mode of faulting does not correlate with the presence or absence of shallow seismicity and thus, low normal stress does not account for the observed upper stability transition. In the second case, pore pressure changes and dilatancy hardening serve only to temporarily arrest slip. As pore pressure equilibrates, seismic failure continues [e.g., Sibson, 1985] and hence, the long-term stability of sliding is not affected.

\section{Stability of Frictional Slip}

Frictional slip within rocks occurs in two distinct modes, namely stable sliding and stick slip [Brace and Byerlee, 1966]. Recently, a fundamental understanding of frictional stability has been put forth in the form of the constitutive laws proposed by Dieterich [1979] and Ruina [1983]. When the constitutive laws are coupled with the elastic interaction that occurs between the slip surface and the loading system, the intrinsic stability of the system can be determined [Dieterich, 1979; Ruina, 1983; Gu et al., 1984]. An increasing frictional resistance with slip velocity (velocity strengthening) always leads to stable slip, whereas velocity weakening can result in stable or unstable slip depending on whether the stiffness of the loading system is above (stable) or below (unstable) a critical stiffness $\left(K_{c r}\right) . K_{c r}=-(a-b) \sigma / L$ where $(a-b)$ is the change in steady-state frictional resistance with slip rate (V); (a-b) $=\mathrm{d} \mu \mathrm{ss} / \mathrm{d} \ln V, \sigma$ is normal stress, and $L$ is the characteristic decay distance upon a step change in slip rate [Dieterich, 1979; Ruina, 1983].

The transition from stable sliding to stick slip in laboratory samples is known to depend upon the presence of gouge [e.g., Byerlee and Summers, 1976]. Thus, as with Tse and Rice's [1986] work showing a stability transition with temperature, a stability transition can be attributed to the presence of gouge. Data from Marone et al. [1987] and Blanpied et al. [1987] support this contention. In Figure 1 (a-b) is plotted as a function of normal stress (Marone et al., in prep.) and ranges between about 0.006 and 0.002 , decreasing with normal stress. The gouge had been compacted prior to the measurements. The data in Figure 1 indicate that velocity strengthening is observed when slip is forced to occur within thick gouge. Experiments at lower normal stress and using thinner gouge layers have shown velocity weakening [Dieterich, 1981], as have experiments using initially bare rock surfaces [Dieterich, 1979; Tullis and Weeks, 1986]. Taken together, these data indicate a fundamental difference in stability when slip occurs within thick unconsolidated material as opposed to between solid surfaces or surfaces separated by a thin layer of highly 


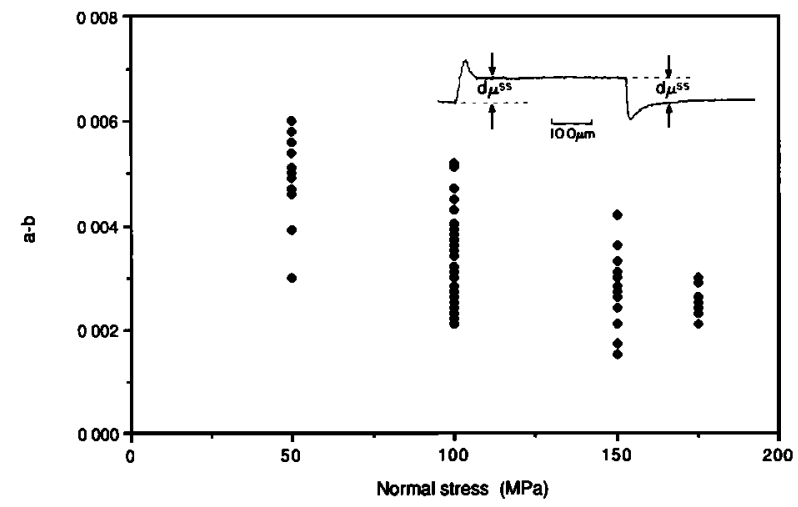

Fig. 1. The slip-rate dependence of friction is plotted as a function of normal stress. (See text for definition of a-b.) The data are for a $4.0 \mathrm{~mm}$ thick layer of quartz gouge and slip velocities between 0.01 and 10.0 microns sec $^{-1}$. Steady-state velocity strengthening is observed over the normal stress range of 50 to $175 \mathrm{MPa}$. Inset shows the coefficient of friction over two $10 \mathrm{x}$ changes in slip rate.

consolidated gouge. If natural faults contain unconsolidated gouge within their shallow regions, they may exhibit stable slip within those regions and unstable slip below the depth at which the gouge becomes consolidated/indurated.

Observations of Seismic Frequency with Depth

To investigate the depth dependence of seismicity, accurate hypocentral locations are required. To avoid biasing against shallow seismicity, we have used data from detailed microearthquake studies in which dense portable networks and local velocity models were used. These studies provide high resolution, $\pm 1 \mathrm{~km}$, hypocentral locations. In addition, "A" and "B" quality data were used for a few areas. Comparisons of these data [Doser and Kanamori, 1986] with those from local surveys [e.g., Gilpin and Lee, 1978] indicates that they are not biased against shallow events. Seismic data collected for a region over a number of years can be used directly to infer variations in frictional, or rheologic, properties with depth [e.g., Sibson, 1984]. Aftershock surveys also provide information on the depth variation of frictional properties. A potential problem with aftershocks, however, is that an absence of shallow seismicity may simply reflect a lack of loading by the mainshock. Therefore, we do not consider aftershock sequences for unusually deep events.

Figure 2 shows the depth distributions of microearthquakes for well-developed and poorly-developed faults. The transition from aseismic to seismic slip is taken as the depth below which $90 \%$ of the seismicity occurred.

\section{Well-Developed Faults}

The distribution of microearthquake depths within the Imperial Valley for 1977-1983 are shown in Figure 2 (see caption for references). The data show that seismicity was confined between about 4-14 km and exhibits an upper cutoff at about $6 \mathrm{~km}$. The Imperial Valley is overlain by a thick sedimentary layer of unconsolidated material [Fuis et al., 1982] and the upper cutoff in seismicity shows a close
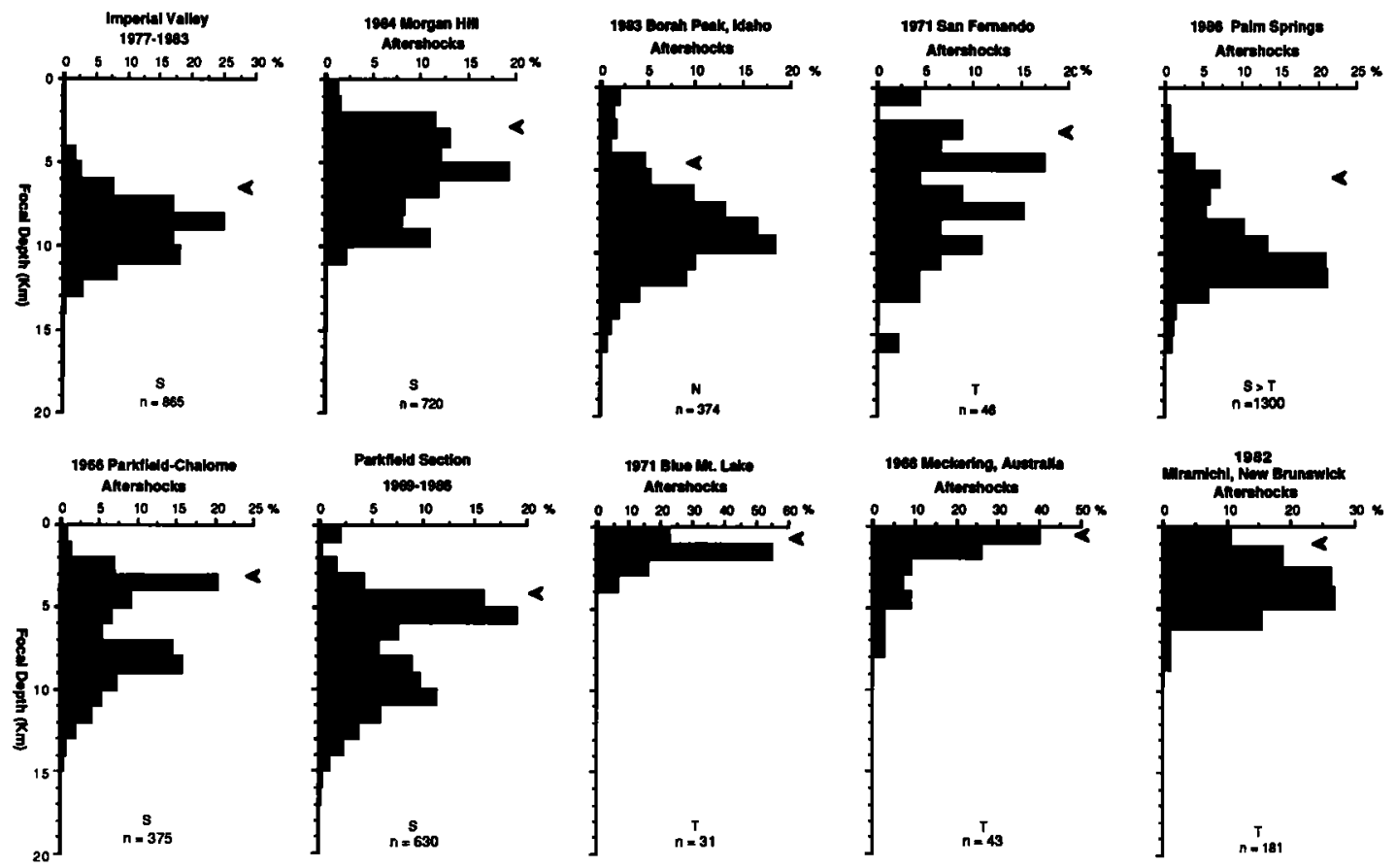

Fig. 2. Earthquake depth distributions along well developed and poorly developed faults. Arrows define the upper cutoff in seismicity. The dominant faulting mode (T, thrust; $S$, strike-slip; $N$, normal) is shown for each sequence. The data show that faults with well-developed gouge zones exhibit an upper cut off in seismicity at between 3-5 km, whereas faults without significant gouge zones exhibit seismicity throughout their upper extents (data from upper left: Doser and Kanamori [1986]; Cockerham and Eaton [1987]; Richins et al., [1987]; Whitcomb et al., [1973]; Caltech Catalog, A quality [1986]; Eaton et al., [1970]; Poley, [1987]; Sbar et al., [1972]; Langston, [1987]; Wetmiller et al., [1984]. 
correlation with the bottom of this layer [Doser and Kanamori, 19861. The effect of the sediments in suppressing seismicity in this area is independently confirmed by the coseismic behavior of the 1979 Imperial Valley earthquake. A kinematic model inverted from accelerometer data by Archuleta [1984] shows that most of the moment release in that earthquake was confined to the $4-14 \mathrm{~km}$ basement layer, and slip velocities were sharply reduced in the sediments. A dynamic model that simulated Archuleta's results was produced by Quin and Boatwright (in prep.). This model shows that a negative stress drop, which implies velocity strengthening, is required in the sediments to reproduce the kinematic results of Archuleta. In addition, Crook [1984] found that after-slip within Imperial Valley was confined to the upper $3 \mathrm{~km}$. This is consistent with velocity strengthening within this region, since velocity strengthening acts to arrest co-seismic slip, resulting in a slip deficit that upon relaxation produces after-slip.

The aftershocks of the 1984 Morgan Hill earthquake show an upper cutoff in seismicity at about $3 \mathrm{~km}$. Blumling et al. [1985] did a seismic refraction study in this area and determined the width of the fault zone to be $1-2 \mathrm{~km}$. They superimposed the aftershocks of the 1979 Coyote Lake earthquake [Reasenberg and Ellsworth, 1982] on their crustal structure and found that nearly all shallow earthquakes were located in the high velocity layers below about $3 \mathrm{~km}$.

The 1983 Borah Peak earthquake occurred along a major normal fault (the Lost River fault) within the intermountain seismic belt. The aftershocks had normal focal mechanisms, were concentrated at 9-10 km, and show an upper cutoff at 4$5 \mathrm{~km}$. The aftershock sequence for the 1971 San Fernando earthquake is also plotted in Figure 2. These were thrust events and they show an upper cutoff in seismicity at 3-4 km.

The aftershocks of the 1966 Parkfield earthquake are plotted in Figure 2 along with background seismicity from 19691986. For the 1966 event, co-seismic slip was confined to a region between about 4 and $10 \mathrm{~km}$ depth and although significant after-slip occurred at the surface [Scholz et al., 1969] aftershocks in the region were confined below $4 \mathrm{~km}$.

\section{Poorly-Developed Faults}

The 1971 Blue Mt. Lake earthquake along with the 1968 Meckering, Australia; and 1982 Miramichi, New Brunswick earthquakes occurred in intraplate settings and along faults that do not have significant net slip. The aftershocks at Blue Mt. Lake were confined to the region between $0-4 \mathrm{~km}$ depth and $90 \%$ of the seismicity occurred below the top $\mathrm{km}$. Langston [1987] analyzed the foreshocks and aftershocks of the Meckering earthquake and determined hypocentral depths to within 1-2 $\mathrm{km}$ using depth phases and synthetic seismograms. The depths he determined using SP-P times show an upper cutoff at $0-1 \mathrm{~km}$. The Miramichi earthquake occurred in an area of the Northern Appalachin Mts. where crystalline rocks are cut by a number of poorly-developed faults [Wetmiller et al., 1984]. The aftershocks show that seismicity occurred throughout the upper $6 \mathrm{~km}$.

\section{Subduction Zone Earthquakes}

Byrne et al. [1988] present data for the relationship between seismicity and topography for several subduction zones.
They show that a seismic front (transition from seismic to aseismic slip) is commonly observed at about the position of the outer-arc high. They attribute the outer-arc high to a change in the critical taper of the accretionary wedge due to stronger material directly below which forms a "backstop" for the unconsolidated material comprising the accretionary wedge. Slip is seismic arcward and deeper than the outer-arc high, whereas slip is aseismic within the accretionary wedge and shallow subduction zone. The seismic front, and upper cutoff in seismicity, therefore, appears to be controlled by the transition from unconsolidated material within the accretionary wedge to consolidated material which makes up the backstop.

\section{Discussion and Conclusions}

Where shallow crustal structure is known in detail, seismicity shows an upper cutoff which coincides with a transition from low seismic velocity (unconsolidated) sediments to competent material. The low normal stress argument for an upper stability transition is not consistent with this observation nor with the shallow seismicity observed along poorly-developed faults. In addition, modeling of co-seismic and post-seismic slip of the 1979 Imperial Valley earthquake indicates velocity strengthening within the unconsolidated sediments. These observations are consistent with the idea that the upper cutoff in seismicity along well-developed faults is the result of a transition from inherently-stable velocity strengthening within the shallow unconsolidated gouge to velocity weakening within the consolidated material below. The seismic front observed along some subduction zones is also consistent with a stability transition due to the presence of unconsolidated material.

It has long been known that the accumulation of wear material tends to stabilize slip in laboratory samples. Recent laboratory friction studies support this observation in that slip within thick gouge exhibits inherently-stable velocitystrengthening behavior, whereas bare rock surfaces and thin gouge layers show potentially unstable velocity weakening. Which of these cases is a more appropriate analog for natural faults remains poorly understood, however, the available data from natural faults support the idea that thick unconsolidated gouge layers are an appropriate analog for at least the shallow portions of well-developed faults.

Acknowledgements. We thank Paul Reasenberg, Rick Lester, Catherine Poley, John Armbruster, and Bob Wetmilller for help with obtaining hypocentral data. Barry Raleigh, David Simpson, Lynn Sykes, and an anonymous reviewer are thanked for reviews. LDGO contribution 4304.

\section{References}

Archuleta, R.J., A faulting model for the 1979 Imperial Valley earthquake, J. Geophys. Res., 89, 4559-4585, 1984.

Brace, W.F., and J.D. Byerlee, Stick-slip as a mechanism for earthquakes, Science, 153, 990, 1966.

Blanpied, M.L., T.E. Tullis, and J.D. Weeks, Contrasting velocity dependence of granite friction: initially bare surfaces vs. simulated gouge, Eos Trans. 68 AGU, 1987.

Blumling, P., W.D. Mooney, and W.H.K.Lee, Crustal structure of the southern Calaveras fault zone, central 
California, from seismic refraction investigations, $B$ ull. Seismol. Soc. Am., 75, 193-209, 1985.

Byerlee, J., and R. Summers, A note on the effect of fault gouge thickness on fault stability, Int. J. Rock Mech. Mining Sci. Geomech. Abstr., 13, 35-36, 1976.

Byrne, D.E., D.M. Davis, and L.R. Sykes, Loci and maximum size of thrust earthquakes and the mechanics of the shallow region of subduction zones, Tectonics, in press, 1988.

Cockerham, R.S., and J.P. Eaton, The earthquake and its aftershocks, April 24-September 30, 1984, U.S.G.S. Bull., 1639, 15-28, 1987.

Crook, C.N., Geodetic measurements of horizontal crustal deformation associated with the October 15, 1979 Imperial Valley California earthquake, $\mathrm{Ph}$. D. Thesis, 240 pp., Univ. London, 1984.

Dieterich, J.H., Modeling of rock friction: 1 . Experimental results and constitutive equations, J. Geophys. Res., 84, 2161-2168, 1979.

Dieterich, J.H., Constitutive properties of faults with simulated gouge, in Mechanical Behavior of Crustal Rocks, Geophysical Monograph 24, pp. 103-120, Am. Geophys. Union Washington, D.C., 1981.

Doser, D.I., and H. Kanamori, Depth of seismicity in the Imperial Valley region 1977-1983 and its relationship to heat flow, crustal structure, and the October 15, 1979 earthquake, J. Geophys. Res., 91, 675-688, 1986.

Eaton, J.P., W.H.K. Lee, and L.C. Pakiser, Use of microearthquakes in the study of the mechanics of earthquake generation along the San Andreas fault in central California, Tectonophysics, 9, 259-282, 1970.

Fuis, G.S., W.D. Mooney, J.H. Healy, G.A. McMechan, and W.J. Lutter, Crustal structure of the Imperial Valley region, the Imperial Valley, California, earthquake of October 15, 1979, USGS Prof. Pap., 1254, 25-49, 1982.

Gilpin, B, and T.C. Lee, A microearthquake study in the Salton Sea geothermal area, California, Bull. Seismol. Soc. Am., 68, 441-450, 1978.

Gu, J.C., J.R. Rice, A.L. Ruina, and S.T. Tse, Slip motion and stability of a single degree of freedom elastic system with rate and state dependent friction, J. Mech. Phys. Sol., 32, 167-196, 1984.

Langston, C.A., Depth of faulting during the 1968 Meckering, Australia earthquake sequence determined from waveform analysis of local seismograms, $J$. Geophys. Res., 92, 11561-11574, 1987.

Marone, C., C.H. Scholz, and C.B. Raleigh, Constitutive modeling and frictional behavior of thick gouge layers, Eos Trans. 68 AGU, 1987.

Poley, K, Catalog of relocated hypocenters for the Parkfield section of the San Andreas, USGS, 1987.

Reasenberg, P., and W.L. Ellsworth, Aftershocks of the Coyote Lake, Califomia, earthquake of August 6, 1979: a detailed study, J. Geophys. Res., 87, 10637-10655, 1982.

Richins, W.D., James C. Pechmann, Robert B. Smith, Charley J. Langer, Susan K. Goter, James E. Zollweg, and John J. King, The 1983 Borah Peak, Idaho earthquake and its aftershocks, Bull. Seismol. Soc. Am., 77, 694-723, 1987.

Robertson, E.C., Relationship of fault displacement to gouge and breccia thickness, Society of Mining Engineers, American Institute of Mining Engineers Transactions, 274, 1426-1432, 1983.

Ruina, A., Slip instability and state variable friction laws, $J$. Geophys. Res., 88, 10359-10370, 1983.

Sbar, M.L., J. Armbruster, and Y.P. Aggarwal, The Adirondack, New York, earthquake swarm of 1971 and tectonic implications, Bull. Seismol. Soc. Am., 62, 13031317, 1972.

Scholz, C.H., M. Wyss, and S.W. Smith, Seismic and aseismic slip on the San Andreas fault, J. Geophy. Res., 74, 2049-2069, 1969.

Scholz, C.H, Wear and gouge formation in brittle faulting, Geology, 15, 493, 1987.

Sibson, R.H., Fault rocks and fault mechanisms, J. Geol. Soc. London, 133, 191-214, 1977.

Sibson, R.H., Roughness at the base of the seismogenic zone: contributing factors, J. Geophys. Res., 89, 57915799, 1984.

Sibson, R.H., Stopping of earthquake ruptures at dilational fault jogs, Nature, 316, 248-251, 1985.

Tse, S.T., and J.R. Rice, Crustal earthquake instability in relation to the depth variation of frictional slip properties, J. Geophys. Res., 91, 9452-9472, 1986.

Tullis, T.E., and J.D. Weeks, Constitutive behavior and stability of frictional sliding of grainite, Pure Appl. Geophys., 124, 383-414, 1986.

Wetmiller, R.J., F.M. Anglin, J.S. Hasegawa, and A.E. Stevens, Aftershock sequences of the 1982 Miramich, New Brunswick earthquakes, Bull. Seismol. Soc. Am., 74, 621-653, 1984.

Whitcomb, J.H., C.R. Allen, J.D. Garmany, and J.A. Hileman, San Fernando earthquake series, 1971: focal mechanisms and tectonics, Rev. Geophys. Space Phys., 11, 693-730, 1973.

C. Marone and C. H. Scholz, Lamont-Doherty Geological Observatory, Palisades, NY 10964.

(Received February 8, 1988;

revised April 25, 1988;

accepted April 26, 1988.) 